\title{
Effectiveness of a novel, completely biomaterial valved pulmonary arterial conduit: An in vivo study
}

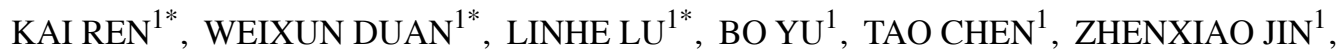 \\ YIMIN ZHAO $^{2}$, DINGHUA YI ${ }^{1}$, SHIQIANG YU ${ }^{1}$ and XUFENG WEI ${ }^{1}$ \\ ${ }^{1}$ Department of Cardiovascular Surgery, Xijing Hospital, The Fourth Military Medical University, Xi'an, Shaanxi 710032; \\ ${ }^{2}$ Ministry of Product Development, Hangzhou Jiahe Zhongbang Biotechnology \\ Co., Ltd., Hangzhou, Zhejiang 311100, P.R. China
}

Received December 4, 2019; Accepted February 28, 2020

DOI: $10.3892 /$ etm.2020.8908

\begin{abstract}
As a pre-clinical assessment, the present study aimed to investigate the safety and effectiveness of a novel valved pulmonary arterial conduit constructed entirely from biomaterials by transplanting it in the outflow tract of the right ventricle in sheep. Under extracorporeal circulation, the valved pulmonary arterial conduit was used to replace the pulmonary artery of sheep with a beating heart. The performance was assessed at 30,90 and 180 days post-surgery. Hemodynamic and structural changes were evaluated, and safety was assessed after 180 postoperative days. The hemodynamic effect and biosafety of the implant were further evaluated by observing the changes in various pressure indicators of the heart, echocardiographic results, anatomical and pathological examination results, liver and kidney functions, routine blood tests, a blood coagulation test, and other test results following implantation of the purely biotic valved conduit. The conduit was successfully implanted in 12 sheep and no mortality occurred postoperatively. During the 180-day follow-up, there was no obvious stenosis or regurgitation of the right ventricular outflow tract and pulmonary valve after valved conduit implantation. The findings of autopsy, pathology and laboratory examinations were unremarkable. The implantation of this biosynthetic vascular graft into animals meets the safety and effectiveness requirements for clinical application. This pulmonary arterial conduit has potential clinical application for children with complex congenital heart disease who
\end{abstract}

Correspondence to: Dr Xufeng Wei or Dr Shiqiang Yu, Department of Cardiovascular Surgery, Xijing Hospital, The Fourth Military Medical University, 127 Changle West Road, Xincheng, Xi'an, Shaanxi 710032, P.R. China

E-mail: weixf2004@hotmail.com

E-mail: yushiq@fmmu.edu.cn

*Contributed equally

Key words: congenital heart disease, completely biomaterial valved pulmonary arterial conduit, hemodynamics, sheep, transplantation require pulmonary artery reconstruction to achieve a radical cure.

\section{Introduction}

Approximately 1.5 million children in China have congenital heart diseases (CHDs) and more than 0.2 million children with CHD are born annually (1). These cases include several types of complex CHD, such as trilogy of Fallot, tetralogy of Fallot, double outlet right ventricle, transposition of the great arteries, pulmonary artery atresia and common arterial trunk (2). It has been reported that $5-10 \%$ of these children require pulmonary artery reconstruction for survival $(3,4)$.

Using a valved conduit to reconstruct the pulmonary artery could save the lives of children, greatly improve the effectiveness of surgical treatments for such CHDs and increase the long-term quality of life (5-10). To date, several materials, including autologous pericardium, xenograft materials, allogeneic valved aortic conduit and artificial valved conduit, have been used, but conduits constructed from ideal materials have yet to become available. Currently, several valved right ventricle conduits, such as the Synergraft valve, bovine Contegra valved conduit, bicuspid valved polytetrafluoroethylene conduit and BIOVALVE, are used in clinical practice in other countries, but they remain unavailable in China (5-10).

Considering the limited lifespan of the current bioprosthetics and shortage of heart valve donors, alternatives such as animal tissues have been suggested as attractive options because animals could provide an unlimited source of tissues for xenotransplantation (11-13). Bovine pericardium has been widely used as a supplementary implantation material for repair in cardiovascular surgeries and it has withstood over 40 years of testing $(14,15)$. Bovine pericardium is more convenient to use, inexpensive, safer, more reliable and widely available, compared with other artificial repair materials.

Bioprosthetic valves made of bovine pericardium with chemical modifications have become widely accepted as artificial bioprosthetic valves because of their good durability $(5,6,9)$. Nevertheless, there is a risk of hyperacute and acute rejection or vascular injury of the xenogeneic tissues. Therefore, complete removal, or at least inactivation of the antigens and nucleic acid remnants of the original resident 
cells, is crucial. To do so, tissues must be decellularized using a combination of physical agents, detergents, enzymes and chemical compounds (16). Nevertheless, the extracellular matrix (ECM), which is essential for correct tissue function, should be left as intact as possible in terms of architecture, ultrastructure, mechanical integrity and biological activity. Indeed, the ultrastructure and composition of the ECM influence cell mitogenesis, chemotaxis and differentiation, and play important roles for integration into the host organ $(17,18)$. Studies performed in the liver (19), respiratory tract (20), nerves (21), adipose tissue (22) and mammary glands (23) have shown that such integration is possible.

A new valved pulmonary arterial conduit, constructed entirely of biomaterials and developed by Jiahe Zhongbang Biotechnology Co., Ltd. is made of bovine pericardium that has undergone decellularization by glutaraldehyde, de-immunogenicity and a series of anti-calcium modifications, followed by bionic structural designing and suturing. Its testing requires large animals that can tolerate cardiopulmonary bypass surgery. Sheep have hemodynamic and blood coagulation system characteristics and laboratory indicators similar to those of humans. They are easy to manage and not susceptible to infection following surgery. Long-term feeding is relatively easy and their long-term survival rate is high. Therefore, sheep were selected as the experimental animal for use in the present study, which aimed to conduct a pre-clinical assessment of this new conduit by transplanting it in the outflow tract of the sheep right ventricle in order to assess its safety profile and hemodynamics.

\section{Materials and methods}

Biomaterial valved pulmonary arterial conduit. Design. On the basis of collected clinical data on heart valve dynamic parameters, the rudimentary appearance of the bioprosthetic valve was derived by analyzing the natural form of the human heart valve. A bioprosthetic valve parametric design platform was then constructed and computer-aided industrial design parametric software (self-designed) was used to create the spatial form that fulfilled the spatial geometry equations. Consequently, a series of dimensional parameters with higher accuracy was obtained for valve cusp parametric model construction, and finite element analysis software ABAQUS 6.13 (Dassault Systemes SE) was used to perform stress analysis on the changes in valve cusp parameters after applying various configurations. The valved conduit was generated by mimicking adult pulmonary artery and valve using a bionic structural design consisted of proximal and distal conduits, with the internal diameter being identical in various segments from the entry point to the exit point $(8-22 \mathrm{~mm})$. A bovine jugular vein containing a trileaflet venous valve was utilized for the proximal conduit, while bovine pericardium that had undergone decellularization, removal of immunogenicity and a series of anti-calcification modifications was used for the segment from the superior margin of the valve to the distal conduit.

Decellularization. Bovine pericardium obtained from a normal cow within $2 \mathrm{~h}$ of slaughter was placed in D-Hanks solution at $4^{\circ} \mathrm{C}$ and stripped of fat and muscle tissue. Subsequently, the pericardium was washed twice with PBS, soaked in $0.3 \%$ glutaraldehyde (GA) at room temperature for $48 \mathrm{~h}$ and stored in $0.5 \% \mathrm{GA}$ solution at $4^{\circ} \mathrm{C}$ before further processing.

Chemical anti-calcification treatment. The GA-treated bovine pericardium was washed twice with $\mathrm{PBS}$, treated with $8 \%$ epichlorohydrin for $48 \mathrm{~h}$ at $25^{\circ} \mathrm{C}$, washed twice again with PBS, treated with 2,3-butanediol at $25^{\circ} \mathrm{C}$ for $120-240 \mathrm{~h}$ and stored in $0.5 \% \mathrm{GA}$ solution at $4^{\circ} \mathrm{C}$ before further use.

Stitching. A custom-made elastic band cutting knife was used to cut the bovine pericardium into strips along a direction parallel to the pericardial fibers. For each strip, thickness at three fixed points was measured using a leather thickness gauge. Pre-punched holes created by laser drilling ensured a uniform stitching pitch, uniform load and minimum stress concentration. The pericardium was stitched using polyester sutures; no synthetic fibers were used in the stitching process. Once the pericardium had softened, it could be cut into strips of various sizes. In addition, standardization, efficiency and stability of product quality during the stitching process were enhanced.

Animal model. A total of 14 healthy adult male sheep (age, 10-12 months; weight, 51 $+5.4 \mathrm{~kg}$; Xi'an Dilepu Biological Resource Development, Co., Ltd.) were used in the study, and kept at the Animal Center of the Experimental Surgery Department, Xijing Hospital, under normal temperature conditions $\left(25^{\circ} \mathrm{C}\right.$ and $70 \%$ humidity). The sheep fold was cleaned twice daily. Regular feeding was provided; the sheep had free access to food and water. All sheep were quarantined for 7 days before the experiments and their activities and feeding behaviors were monitored during this period. All sheep were eligible for the experiments after approval from a veterinarian. Animals with abnormalities were handled under the guidance of the clinical veterinarian and director of this study. The sheep were fasted for $12 \mathrm{~h}$ pre-operatively. Selection, feeding and monitoring of the sheep, as well as the study protocol, were approved by the Animal Ethics Committee of the Fourth Military Medical University. Two of the sheep were used as sham controls.

Anesthesia. General anesthesia was induced by the muscular injection of $8 \mathrm{mg} / \mathrm{kg}$ ketamine and 0.6-0.9 mg scopolamine and an intravenous line was established. Then, $1-2 \mathrm{mg} / \mathrm{kg}$ propofol and $1-2 \mu \mathrm{g} / \mathrm{kg}$ fentanyl were intravenously injected (24). Tracheal intubation was conducted to establish an artificial airway and a ventilator was used with the following respiratory parameters: Tidal volume, $10-12 \mathrm{ml} / \mathrm{kg}$ and frequency, 10-16 bpm. Isoflurane (1-2\%) was used for anesthesia maintenance. Femoral artery puncture was conducted to monitor arterial blood pressure. Electrocardiogram monitoring was performed.

Surgery. An incision was made at the left side of the chest and the left fourth rib was removed. Vena cava catheterization was conducted through the right auricle. The arterial catheter was sutured to the ascending aorta. A drainage tube was inserted into the right side of the heart at $1 \mathrm{~cm}$ below the pulmonary valve ring. Heparin (3-4 mg/kg) was injected to adjust the whole blood activated clotting time to $>480 \mathrm{sec}$. Extracorporeal circulation 


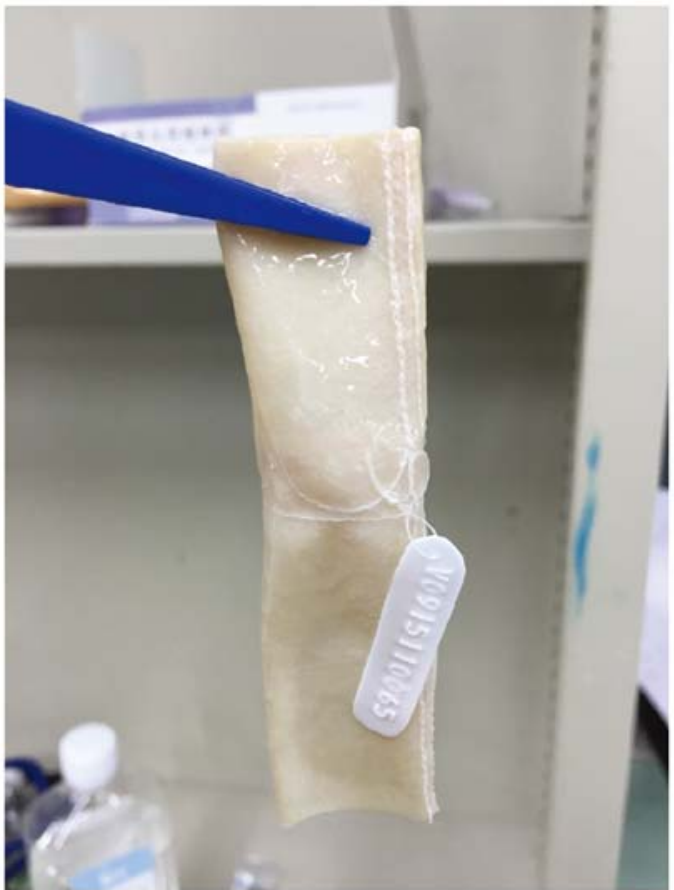

Pre-anesthesia

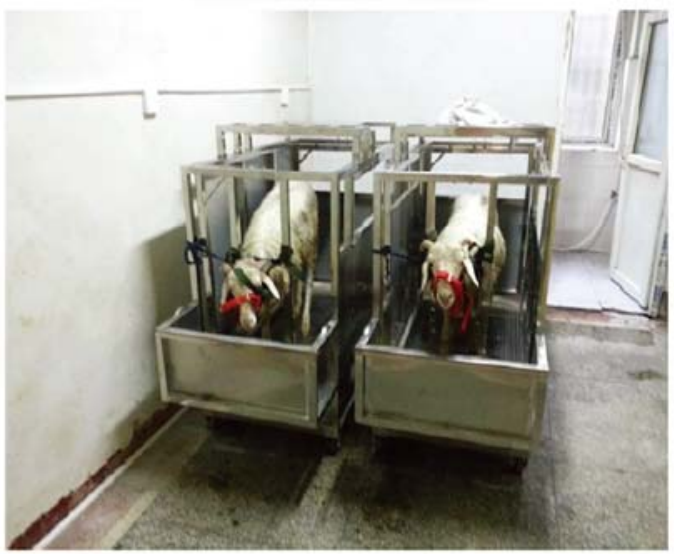

Feeding

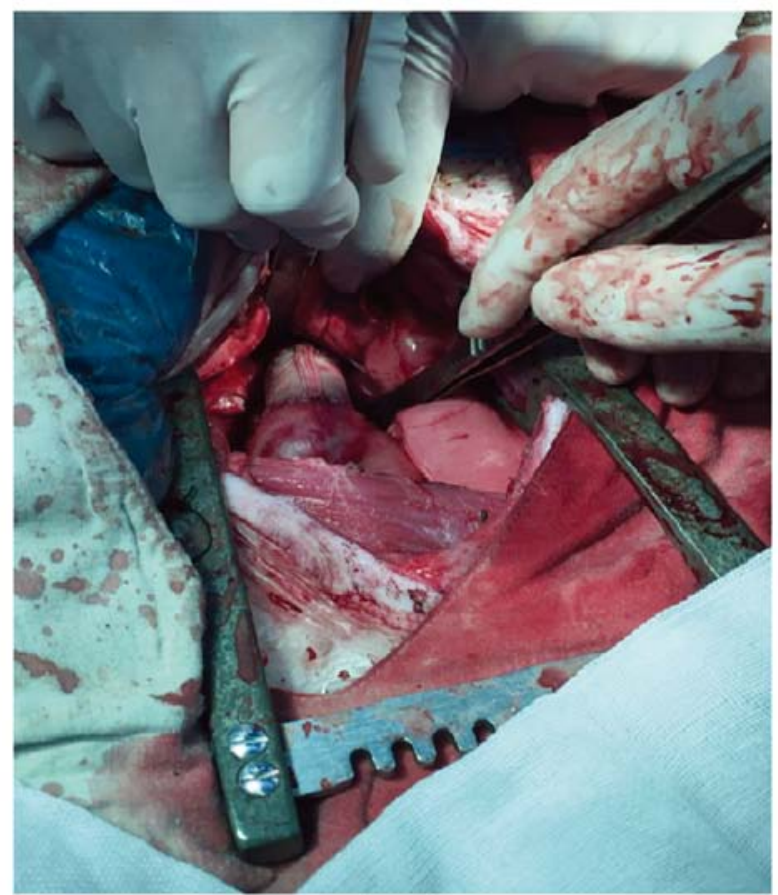

Implantation

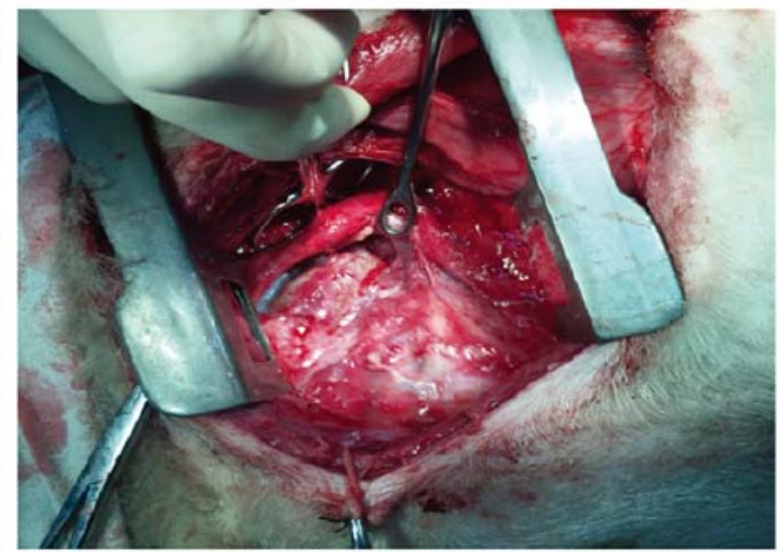

Anatomy

Figure 1. Biomaterial valved pulmonary arterial conduit and sheep prior to and during implantation.

was established after systemic heparinization. The main pulmonary artery space was isolated and the main pulmonary artery diameter was measured. The valved conduits were rinsed with $500 \mathrm{ml} \mathrm{0.9 \%} \mathrm{normal} \mathrm{saline} \mathrm{three} \mathrm{times} \mathrm{(} 5 \mathrm{~min} /$ time). A vascular clamp was used to block the distant pulmonary artery at the site close to the pulmonary artery bifurcation. Then, the pulmonary artery was resected at $1 \mathrm{~cm}$ above the pulmonary artery valve, the three pulmonary artery valve leaflets were removed and an artificial blood vessel with the same diameter as that of the main pulmonary artery was selected. The extracorporeal circulation machine was removed after circulation stabilization. A drainage tube was placed at the left fifth intercostal space and the thoracic cavity was closed layer by layer. Tracheal extubation was performed after anesthetic recovery (Fig. 1).

Post-operative care and follow-up. Animals were fed at $6 \mathrm{~h}$ after tracheal extubation. Daily behaviors of the sheep, namely food and water intake and activities, and their psychological status with regards to stress and dysphoria were monitored postoperatively and recorded. Body weights were measured every 2 weeks. Sheep were sacrificed at $30(n=2), 90(n=2)$ and $180(n=8)$ days postoperatively. Changes in hemodynamics, outflow tract of the right ventricle and pulmonary artery structure were assessed.

From the second day after the surgery, there was no risk of bleeding. Aspirin tablets were mixed into the food for anticoagulation at a dose of $100 \mathrm{mg} / \mathrm{day}$.

Valve conduit function evaluation. Closing and opening of the valves were assessed by ultrasonography and the pressure gradient was also measured. An ultrasound device (Vivid-7; GE Healthcare) was used to monitor right ventricular pressure and distal pulmonary artery pressure before and after implantation. At 30, 60 and 180 days post-implantation, sheep were administered an muscular injection of $8 \mathrm{mg} / \mathrm{kg}$ ketamine under quiet conditions. Right ventricular pressure and distal pulmonary artery pressure were monitored and transpulmonary valve pressure difference was calculated. 

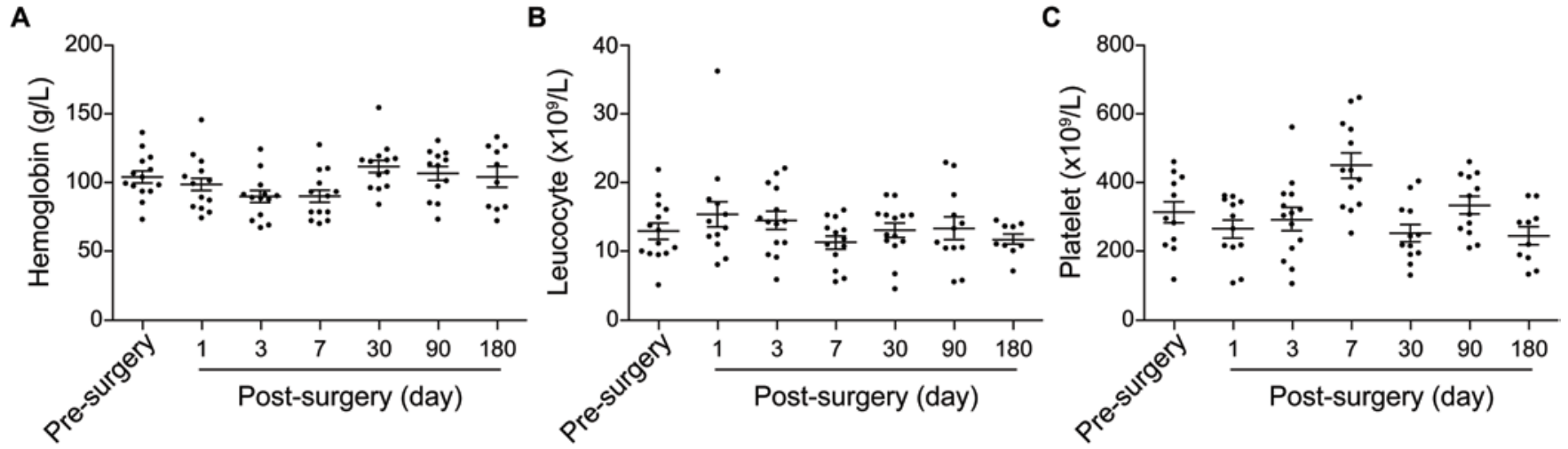

Figure 2. Evaluation of the general condition of the sheep. (A) Hemoglobin levels, (B) white blood cell count and (C) platelet count of the sheep.

To observe the effect of the biomaterial valved pulmonary arterial conduit on the heart after implantation, the pressure and hemodynamic changes of each heart chamber were assessed. The heart was exposed and the central venous and arterial pressures, pulmonary arterial pressure at the distal artificial blood pressure of the right side of the heart, and pressure of the outflow tract of the right ventricle were measured. Pressure gradient over the artificial blood vessel was calculated using the following equation: Pressure gradient $(\mathrm{mmHg})=$ systolic pressure of the outflow tract of the right ventricle-systolic pressure of the distal pulmonary artery.

Valved conduit calcification evaluation. Calcium levels in the artificial biomaterial blood vessel and valves were measured. The samples were dried at $75^{\circ} \mathrm{C}$ until the weight remained constant and then sealed tightly in dry containers. The samples were placed in a $25-\mathrm{ml}$ conical flask with $5 \mathrm{ml}$ mixed acids (nitric acid:perchloric acid, 8:2) and the flask was shaken at $150-180^{\circ} \mathrm{C}$. After the solution cleared, the sample was washed with $1 \%$ nitric acid solution and transferred to a $10-\mathrm{ml}$ scale test tube with a lid. The solution was mixed and the calcium levels were then measured with a graphite furnace atomic absorption spectrometer. The results were recorded as calcium levels by weight $(\mathrm{mg})$ of dry tissue.

Statistical analysis. SPSS 11.10 (SPSS,Inc.) was used for statistical analysis. All data are presented as means \pm standard deviation. Analysis of variance and Tukey's post hoc test were used for comparisons. $\mathrm{P}<0.05$ was considered statistically significant.

\section{Results}

Surgical outcomes. In situ implantation of the artificial biomaterial valved blood vessel was successfully conducted in all 14 sheep with extracorporeal circulation and a beating heart under general anesthesia. The mean operative time was $131 \pm 18 \mathrm{~min}$ and mean extracorporeal circulation time was $35 \pm 8 \mathrm{~min}$. The sheep were able to stand by themselves at $2 \mathrm{~h}$ postoperatively and drink water within $4 \mathrm{~h}$ postoperatively. The drainage tube was removed within $24 \mathrm{~h}$ postoperatively. The mean drainage volume was $70 \pm 30 \mathrm{ml}$. Although the drainage volume was $>400 \mathrm{ml}$ in one sheep, the animal was in good condition and showed stable respiration and circulation; the drainage tube in this sheep was removed 1 day later.
Heart structure and hemodynamics are not affected by post-valved pulmonary arterial conduit implantation. Echocardiography through the heart surface was conducted intraoperatively following the removal of extracorporeal circulation. The biomaterial pulmonary arterial valves of all 14 sheep could open and close freely, surfaces were smooth and no abnormal echo, valve position or activity was detected. The artificial pulmonary artery was patent and the lumen was clear. Color Doppler flow imaging showed normal blood flow velocity through the pulmonary arterial valve, with no evident backflow. No evident accelerated blood flow at the anastomosis of the artificial blood vessel and pulmonary artery was detected. These results suggest that the implantation of the completely biomaterial valved pulmonary arterial conduit did not noticeably affect the heart structure and hemodynamics.

No renal or liver function impairment occur following valved pulmonary arterial conduit implantation. Before and following the surgery, no changes in the levels of hemoglobin $(103 \pm 16$ vs. $104 \pm 24$ g/l; Fig. $2 \mathrm{~A})$, white blood cells $\left(11.4 \pm 2.2 \times 10^{9}\right.$ vs. $9.8 \pm 2.2 \times 10^{9}$ cells/1; Fig. $\left.2 \mathrm{~B}\right)$ or platelets $\left(317 \pm 89 \times 10^{9}\right.$ vs. $292 \pm 71 \times 10^{9}$ platelets/1; Fig. 2 C) caused by hemolysis were found, indicating that the implantation of the biomaterial valved pulmonary arterial conduit did not result in adverse effects, such as evident blood cell destruction or inflammatory responses.

Alanine transaminase (ALT) levels of the sheep increased temporarily on the day after the surgery, but gradually returned to normal. The mean ALT levels 180 days postoperatively were $15 \pm 5 \mathrm{IU} / 1$ (Fig. 3A). Blood urea nitrogen levels did not change significantly postoperatively compared with the preoperative level (Fig. 3B). These results indicate that the biomaterial valved pulmonary arterial conduit implantation did not result in evident renal or liver function impairment.

Pressure gradient over the artificial blood vessel is comparable at pre- or post-valved arterial conduit implantation. The 12 sheep with artificial blood vessels were sacrificed at various different time points after tracheal intubation under general anesthesia. Evident tissue adhesion and substantial bleeding from the right auricle were found in one sheep after the heart was exposed. This sheep was therefore not included in the following statistical analyses. 

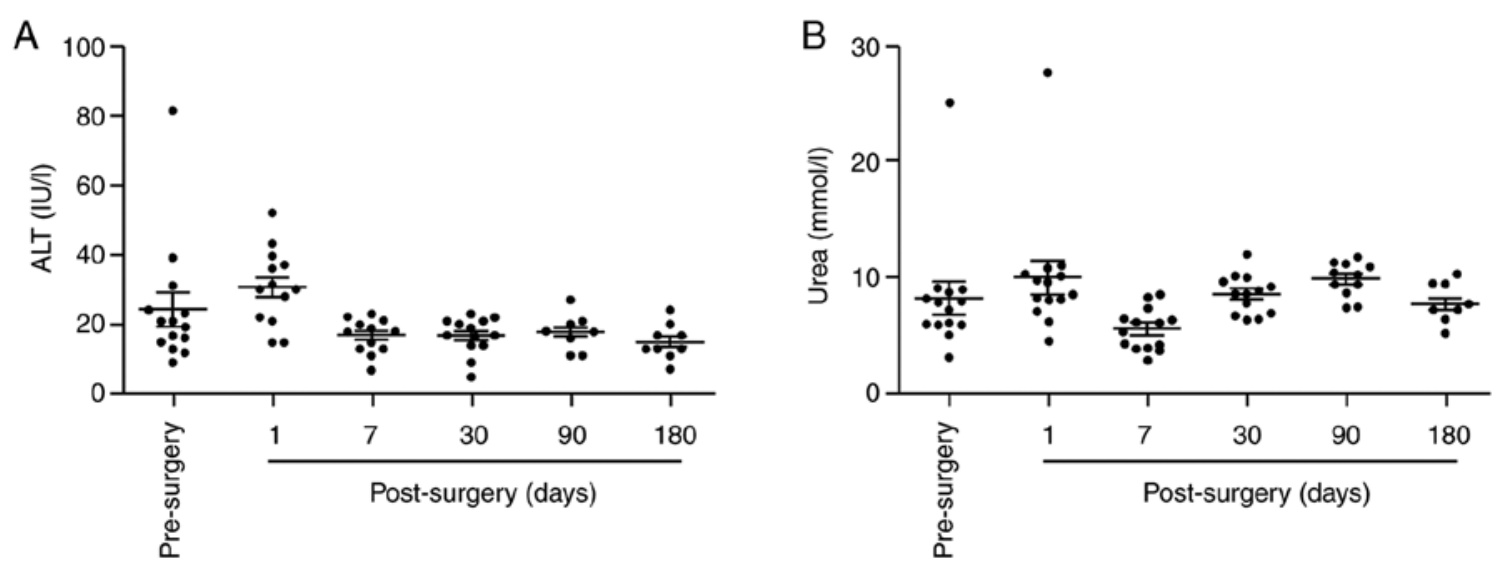

Figure 3. Evaluation of the hepatic condition of the sheep. (A) ALT and (B) blood urea nitrogen levels of the sheep. ALT, alanine aminotransferase.
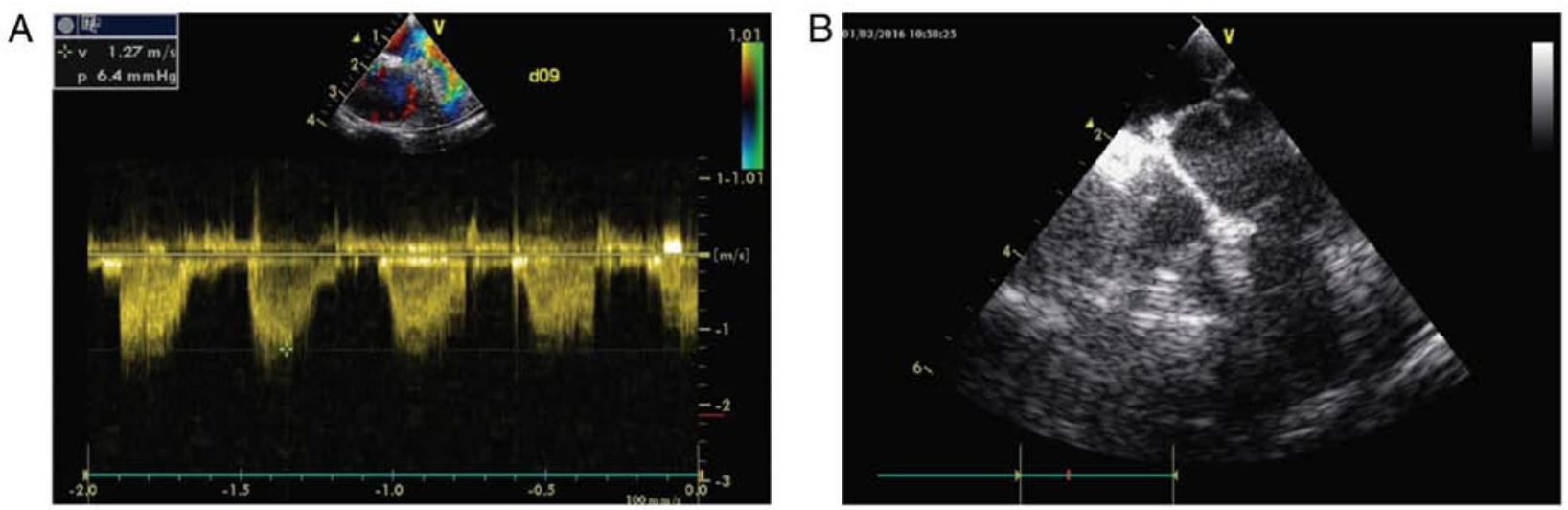

Figure 4. Echocardiographic results after the completely biomaterial valved pulmonary arterial conduit implantation. (A) Doppler ultrasound of the pulmonary artery. (B) Echocardiography examination of the right ventricle.
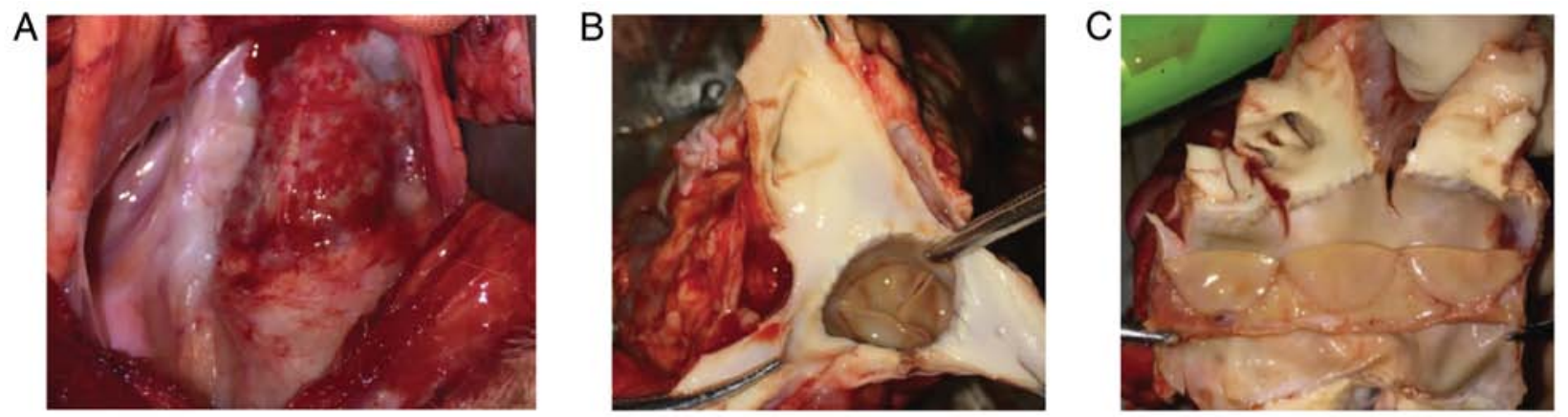

Figure 5. Pathological examinations of the artificial conduits. (A) The surface of artificial conduit after dissection. (B) The inside view of artificial conduit, (C) The view of artificial conduit with a longitudinal section.

The central venous and arterial pressures of the sheep were all normal. The highest pressures of the outflow tract of the pulmonary artery systolic pressure in all sheep were $<30 \mathrm{mmHg}$. No significant changes in the pressure gradient over the artificial blood vessel were detected (Table I). No significant abnormality was identified in pulmonary artery systolic pressure, right ventricle systolic pressure or pressure gradient over the artificial blood vessel after implantation compared with the values before implantation $(\mathrm{P}>0.05)$.
Ultrasound examinations conducted 30 and 90 days postoperatively showed that the biomaterial valves of the pulmonary arteries in all animals could open and close freely, had a smooth surface and were without abnormal echo, position or activity. The artificial pulmonary artery was patent and the lumen was clear. Color Doppler flow imaging revealed normal blood flow velocity through the pulmonary arterial valve, with no evident backflow. No accelerated blood flow at the anastomosis of the artificial blood vessel and pulmonary artery was detected. Ultrasound imaging results are shown in Fig. 4. 
Table I. Hemodynamic changes after reconstruction of the right ventricular artery $(\mathrm{n}=12 ; \mathrm{mmHg})$.

\begin{tabular}{lcc}
\hline Index & $\begin{array}{c}\text { Before } \\
\text { surgery }\end{array}$ & $\begin{array}{c}\text { After } \\
\text { surgery }\end{array}$ \\
\hline Pulmonary artery systolic pressure & $23 \pm 6$ & $24 \pm 5$ \\
Right ventricle systolic pressure & $36 \pm 5$ & $39 \pm 4$ \\
Pressure gradient over artificial & $13 \pm 2$ & $12 \pm 4$ \\
blood vessel & & \\
\hline $1 \mathrm{mmHg}=0.1133 \mathrm{kPa}$. & & \\
\hline
\end{tabular}

Examinations on postoperative day 180 showed that the biomaterial valve of the pulmonary artery in one animal could not close and open freely. In addition, valve thickening and enhanced echo were detected. Blood flow velocity through the pulmonary arterial valve was slightly increased and mild backflow through the pulmonary arterial valve was detected. No pulmonary arterial valve abnormalities were observed in the other 7 sheep (Fig. 5). These results showed that completely biomaterial valved pulmonary arterial conduit implantation did not result in long-term adverse effects on heart structure and hemodynamic.

No adverse effects, bleeding or infarction are evident following valved pulmonary arterial conduit implantation. The wool of the 12 sheep recovered well. A white sticky liquid was detected in a subcutaneous mass in one sheep, which was not connected to the thoracic cavity. The heart sizes and shapes of all 12 sheep were normal. No evident bleeding or pale areas were observed on the heart surface. Heart chamber sizes were normal. Signs of myocardial infarction, thrombus or mass were not observed. Artificial blood vessel positions and sizes were normal. The artificial vessels were soft and tissue adhesion was detected. Following resection of the longitudinal artificial vessel, it was observed that the valves in one sheep had hardened slightly and exhibited calcium deposition, so the valve activities were suboptimal. By contrast, the valves and blood vessel walls in all other 11 sheep were free from thrombus, mass or calcium deposition. The valves in these 11 sheep were soft and smooth and demonstrated good activity. The blood vessel walls were also soft and smooth, with no evidence of calcification. The lung size and shape of all 12 sheep were normal. Adhesion was found in operative areas in all animals; no edema, bleeding or infarction was detected in other parts of the lungs. Gross shapes of the livers, kidneys and spleens in all 12 sheep were normal; the surfaces of these organs were all smooth, with no signs of bleeding or infarction (Fig. 5). These results showed that the implantation of the biomaterial arterial conduit did not result in evident thermogenesis, embolism or infarction in the organs, as demonstrated by the autopsies.

Histopathological examinations showed partial calcification of the collagenous fiber in one sheep, but no necrosis or degeneration of the fiber tissues of the valves was evident. Histopathological examinations of the heart revealed no evident fibrogenesis or infarction in the heart tissues in all
Table II. Calcium levels in the artificial blood vessels.

\begin{tabular}{lcc}
$\begin{array}{l}\text { Sheep } \\
\text { no. }\end{array}$ & $\begin{array}{r}\text { Calcium levels of } \\
\text { the valve }(\mu \mathrm{g} / \mathrm{mg})\end{array}$ & $\begin{array}{c}\text { Calcium levels of the } \\
\text { conduit }(\mu \mathrm{g} / \mathrm{mg})\end{array}$ \\
\hline 1 & 0.79 & 1.12 \\
2 & 1.09 & 1.01 \\
3 & 1.08 & 0.81 \\
4 & 2.99 & 1.61 \\
5 & 1.43 & 4.02 \\
6 & 27.2 & 2.4 \\
7 & 1.07 & 0.95 \\
8 & 1.06 & 1.08 \\
9 & 0.91 & 0.96 \\
10 & 8.05 & 1.2 \\
11 & 204 & 4.5 \\
12 & 2.51 & 4.21 \\
\hline
\end{tabular}

Sheep nos. 1 and 2 were evaluated at 30 days. Sheep nos. 3 and 4 were evaluated at 90 days. Sheep nos. 5-12 were evaluated at 180 days.

sheep. Examinations of the pulmonary tissues showed that the alveolar structure was generally normal. The tissues of the livers, kidneys and spleens were generally normal, with no evident bleeding or necrosis (Fig. 6). These results showed that the conduit implantation did not result in evident adverse effects on the organs, or evident bleeding or infarction.

Artificial conduit remains free from calcification. The calcium levels in the artificial blood vessels in the 12 sheep are shown in Table II: The calcium levels in the sheep sacrificed on postoperative days 30 and 90 were all $<10 \mu \mathrm{g} / \mathrm{mg}$. For the sheep sacrificed on postoperative day 180 , the calcium levels in the valve were elevated in two of the sheep, at 204 and $27.2 \mu \mathrm{g} / \mathrm{mg}$. Nevertheless, no evident valve stenosis or insufficiency was found in the artificial blood vessels of these two sheep. The highest pressure gradient over the artificial blood vessel was $22.5 \mathrm{mmHg}$, which did not result in adverse effects on hemodynamics. The calcium levels in all the other valves were $<10 \mu \mathrm{g} / \mathrm{mg}$. These results showed that the artificial conduit was free from calcification.

\section{Discussion}

The present study investigated the performance of a new, valved pulmonary arterial conduit prepared using a proprietary method. The conduit has the following characteristics: It consists of a stentless bioprosthetic pulmonary valve and bioprosthetic great vessels, and can be transplanted during cardiovascular surgery for the surgical reconstruction of the right ventricular outflow tract or replacement of non-functioning previously transplanted tracts to treat patients with right ventricular outflow tract anomalies or lesions. Given that it has undergone acellular and immunogenicity removal and serial anti-calcification modification treatment, the conduit is strong and durable. It is sewn with polyester suture from the bovine pericardium without any synthetic fiber, thereby preventing thrombus formation and 


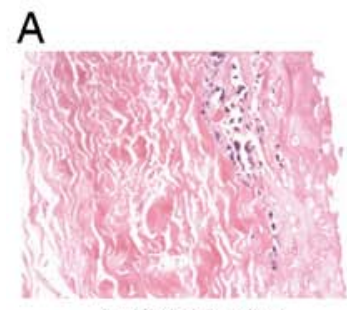

Artificial leaflet

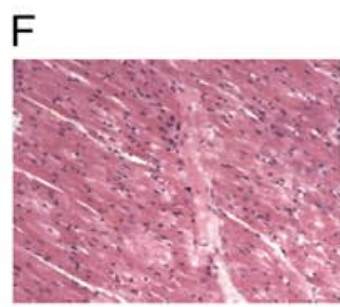

Left atrium

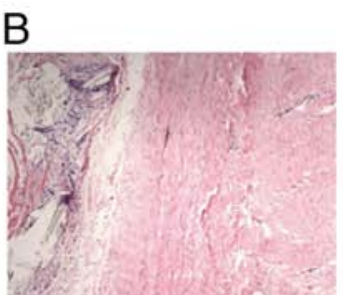

Artificial blood channel

G

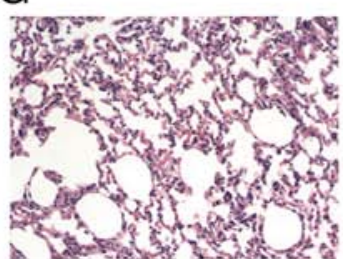

Lung

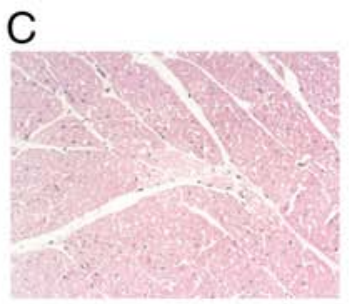

Right ventricular

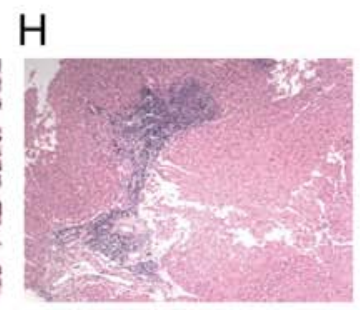

Liver

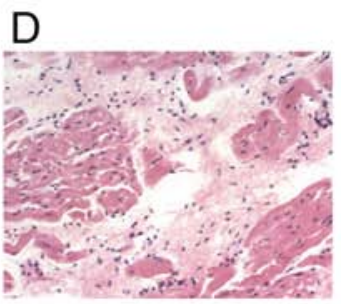

Right atrium

I

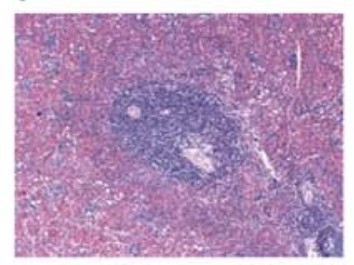

Spleen

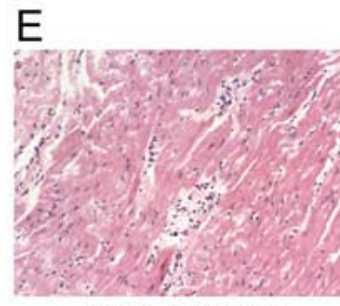

Left ventricular

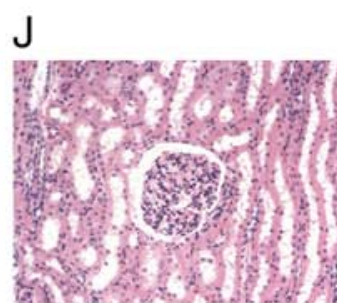

Kidney

Figure 6. Pathological examinations of the implanted valve. (A and B) implanted artificial conduit, (C) right ventricle, (D) right atrium, (E) left ventricle, (F) left atrium, (G) lung, (H) liver, (I) spleen and (J) kidney of the sheep. Magnification, x200.

non-bacterial inflammation caused by the porous structure of synthetic fiber. The results showed that this artificial valved conduit effectively replaced the original pulmonary artery and pulmonary arterial valves of sheep.

Clinicians are looking for graft biomaterials that do not require long-term anticoagulant therapy. With the expansion of the surgical indications of complex CHD, the insufficiency of the available materials for reconstruction of the right ventricular outflow tract has become more evident and is regarded as an important factor restricting the clinical application of such materials, especially for correction surgeries in neonates. Currently, several studies have reported the use of valved bovine jugular veins (25-28), but such conduits have several disadvantages: They are difficult to harvest, easily calcify and tend to be prone to aneurysm-like dilation, severely affecting the surgical outcomes.

In the present study, the new valve pulmonary arterial conduit constructed entirely from biomaterials was used to replace the original pulmonary artery and pulmonary arterial valves. The valves were found to close and open freely, with no severe stenosis or valve insufficiency detected. Additionally, the hemodynamics all met the physiological requirements of the sheep. Furthermore, the calcium levels in the valves of artificial blood vessels were $>10 \mu \mathrm{g} / \mathrm{mg}$ in only two sheep at 180 days postoperatively, but without any evident valve stenosis or insufficiency. In addition, the highest pressure gradient over the artificial blood vessel was $22.5 \mathrm{mmHg}$, which did not result in adverse effects on hemodynamics. No thrombogenesis or associated adverse events were observed, despite the fact that no or low-dose anticoagulant therapy was applied. No evident thrombogenesis or embolism was identified in the organs during autopsy. These results show that this product has high blood compatibility. The results of the present study are consistent with other studies of valved pulmonary arterial conduit implantation in large animal models, albeit using different valved pulmonary arterial conduits $(8,29)$. The conduit has more outstanding anti-calcification characteristics and is biologically safe.
In conclusion, the 6-month follow-up data showed that the implantation of this novel biosynthetic vascular graft into animals was safe and could meet the safety and effectiveness requirements for clinical application. However, as no large-animal model with pulmonary artery stenosis was used, the long-term effect of the valved conduit in such conditions could not be evaluated in the present study. The present authors plan to conduct another study to evaluate the effect of the new valved pulmonary arterial conduit in animal models of diseases, such as pulmonary stenosis and pulmonary regurgitation. For children with complex CHDs requiring pulmonary artery reconstruction to achieve a radical cure, this pulmonary arterial conduit has certain clinical application significance. Due to time constraints and the lack of clinically relevant mature products, a sham control group was used in the present study; however, the number of animals was small and this is recognized as a limitation of this study. The long-term effects and safety of this biological conduit require further study with longer observation periods along with rigorous testing before clinical trials or routine clinical use.

\section{Acknowledgements}

The authors acknowledge the help of Dr Liang Cheng of the Department of Cardiovascular Surgery, Xijing Hospital, The Fourth Military Medical University, Xi'an, Shaanxi for the conception and design of the study.

\section{Funding}

This study was supported by the Project of the National Natural Science Foundation of China (grant no. 31370996).

\section{Availability of data and materials}

The datasets used and/or analyzed during the present study are available from the corresponding author on reasonable request. 


\section{Authors' contributions}

TC conceived and supervised the study. ZJ designed the experiments. DY, SY and XW performed the experiments. BY and YZ analyzed the data. KR, WD and LL wrote the manuscript and acquired, analyzed and interpreted the data. All authors reviewed the results and read and approved the final version of the manuscript.

\section{Ethics approval and consent to participate}

The study protocol was approved by the Animal Ethics Committee of the Air Force Medical University.

\section{Patient consent for publication}

Not applicable.

\section{Competing interests}

YZ is affiliated with Hangzhou Jiahe Zhongbang Biotechnology Co., Ltd., Hangzhou, Zhejiang, the company that developed the valved pulmonary arterial conduit used in the study. No patent or available publication is involved.

\section{References}

1. Pei L, Kang Y, Zhao Y and Yan H: Prevalence and risk factors of congenital heart defects among live births: A population-based cross-sectional survey in Shaanxi province, Northwestern China. BMC Pediatr 17: 18, 2017.

2. Qu Y, Liu X, Zhuang J, Chen G, Mai J, Guo X, Ou Y, Chen J, Gong W, Gao X, et al: Incidence of congenital heart disease: The 9 -year experience of the guangdong registry of congenital heart disease, China. PLoS One 11: e0159257, 2016.

3. Monge MC, Mainwaring RD, Sheikh AY, Punn R, Reddy VM and Hanley FL: Surgical reconstruction of peripheral pulmonary artery stenosis in Williams and Alagille syndromes. J Thorac Cardiovasc Surg 145: 476-481, 2013.

4. Rao PS and Chugh R: A comprehensive approach to congenital heart diseaes. Vijayalakshmi IB, editor. Nel Delhi: Jaypee Brothers Medical Publichers; 2013.

5. Breymann T, Thies WR, Boethig D, Goerg R, Blanz U and Koerfer R: Bovine valved venous xenografts for RVOT reconstruction: Results after 71 implantations. Eur J Cardiothorac Surg 21: 703-710; discussion 710, 2002.

6. Wu L, Wang ZH, Wang WD, Liu WY and Jin F: Experimental study on construction of valved conduits by decellularized bovine jugular vein in vivo. Prog Mod Biomed 2: 246-248, 2011.

7. Takewa Y, Yamanami M, Kishimoto Y, Arakawa M, Kanda K, Matsui Y, Oie T, Ishibashi-Ueda H, Tajikawa T, Ohba K, et al: In vivo evaluation of an in-body, tissue-engineered, completely autologous valved conduit (biovalve type VI) as an aortic valve in a goat model. J Artif Organs 16: 176-184, 2013.

8. Wu H, Xu ZW, Liu XM, Gong D, Wan JY, Xu XF, Zhou ZF and Li WB: An in vivo model of in situ implantation using pulmonary valved conduit in large animals under off-pump condition. Chin Med J (Engl) 126: 4540-4544, 2013.

9. Yuan SM: The Contegra valved bovine conduit: A biomaterial for the surgical treatment of congenital heart defects. Arq Bras Cardiol 99: 1159-1166, 2012 (In English, Portuguese).

10. Zhang $\mathrm{J}$ and Liu Y: Establishment of rabbit carotid artery homograft valved conduits transplantation model. Chin J Exp Surg 2000: 568-569, 2000.

11. Piazza N, de Jaegere P, Schultz C, Becker AE, Serruys PW and Anderson RH: Anatomy of the aortic valvar complex and its implications for transcatheter implantation of the aortic valve. Circ Cardiovasc Interv 1: 74-81, 2008.
12. Ong K, Boone R, Gao M, Carere R, Webb J, Kiess M and Grewal J: Right ventricle to pulmonary artery conduit reoperations in patients with tetralogy of fallot or pulmonary atresia associated with ventricular septal defect. Am J Cardiol 111: 1638-1643, 2013.

13. Boethig D, Thies WR, Hecker H and Breymann T: Mid term course after pediatric right ventricular outflow tract reconstruction: A comparison of homografts, porcine xenografts and contegras. Eur J Cardiothorac Surg 27: 58-66, 2005.

14. Pires AC, Saporito WF, Cardoso SH and Ramaciotti O: Bovine pericardium used as a cardiovascular patch. Heart Surg Forum 2: 60-69, 1999.

15. Neethling WM, Strange G, Firth L and Smit FE: Evaluation of a tissue-engineered bovine pericardial patch in paediatric patients with congenital cardiac anomalies: Initial experience with the ADAPT-treated CardioCel(R) patch. Interact Cardiovasc Thorac Surg 17: 698-702, 2013.

16. Keane TJ, Swinehart IT and Badylak SF: Methods of tissue decellularization used for preparation of biologic scaffolds and in vivo relevance. Methods 84: 25-34, 2015.

17. Dohmen PM, da Costa F, Yoshi S, Lopes SV, da Souza FP, Vilani R, Wouk AF, da Costa M and Konertz W: Histological evaluation of tissue-engineered heart valves implanted in the juvenile sheep model: Is there a need for in-vitro seeding? J Heart Valve Dis 15: 823-829, 2006.

18. Gallo M, Naso F, Poser H, Rossi A, Franci P, Bianco R, Micciolo M, Zanella F, Cucchini U, Aresu L, et al: Physiological performance of a detergent decellularized heart valve implanted for 15 months in Vietnamese pigs: Surgical procedure, follow-up, and explant inspection. Artif Organs 36: E138-E150, 2012.

19. Sellaro TL, Ranade A, Faulk DM, McCabe GP, Dorko K, Badylak SF and Strom SC: Maintenance of human hepatocyte function in vitro by liver-derived extracellular matrix gels. Tissue Eng Part A 16: 1075-1082, 2010.

20. Petersen TH, Calle EA, Zhao L, Lee EJ, Gui L, Raredon MB, Gavrilov K, Yi T, Zhuang ZW, Breuer C, et al: Tissue-engineered lungs for in vivo implantation. Science 329: 538-541, 2010.

21. Karabekmez FE, Duymaz A and Moran SL: Early clinical outcomes with the use of decellularized nerve allograft for repair of sensory defects within the hand. Hand (N Y) 4: 245-249, 2009.

22. Flynn LE: The use of decellularized adipose tissue to provide an inductive microenvironment for the adipogenic differentiation of human adipose-derived stem cells. Biomaterials 31: 4715-4724, 2010.

23. Wicha MS, Lowrie G, Kohn E, Bagavandoss P and Mahn T: Extracellular matrix promotes mammary epithelial growth and differentiation in vitro. Proc Natl Acad Sci USA 79: 3213-3217, 1982.

24. Salama AK: Comparison between ketamine and hyoscine for the management of postoperative catheter-related bladder discomfort: A randomized controlled double-blind study. J Anaesthesiol Clin Pharmacol 33: 76-80, 2017.

25. Brown JW, Ruzmetov M, Rodefeld MD, Vijay P and Darragh RK: Valved bovine jugular vein conduits for right ventricular outflow tract reconstruction in children: An attractive alternative to pulmonary homograft. Ann Thorac Surg 82: 909-916, 2006.

26. Bove T, Demanet H, Wauthy P, Goldstein JP, Dessy H, Viart P, Devillé A and Deuvaert FE: Early results of valved bovine jugular vein conduit versus bicuspid homograft for right ventricular outflow tract reconstruction. Ann Thorac Surg 74: 536-541; discussion 541, 2002.

27. Herijgers P, Ozaki S, Verbeken E, Van Lommel A, Meuris B, Lesaffre E, Daenen W and Flameng W: Valved jugular vein segments for right ventricular outflow tract reconstruction in young sheep. J Thorac Cardiovasc Surg 124: 798-805, 2002.

28. Meyns B, Van Garsse L, Boshoff D, Eyskens B, Mertens L, Gewillig M, Fieuws S, Verbeken E and Daenen W: The Contegra conduit in the right ventricular outflow tract induces supravalvular stenosis. J Thorac Cardiovasc Surg 128: 834-840, 2004.

29. Leyh RG, Wilhelmi M, Rebe P, Ciboutari S, Haverich A and Mertsching H: Tissue engineering of viable pulmonary arteries for surgical correction of congenital heart defects. Ann Thorac Surg 81: 1466-14670; discussion 1470-1471, 2006.

This work is licensed under a Creative Commons Attribution-NonCommercial-NoDerivatives 4.0 International (CC BY-NC-ND 4.0) License. 